\title{
GAMBARAN SELF EFFICACY DAN PENGETAHUAN PADA KLIEN TUBERKULOSIS
}

\section{Self Efficacy and Knowledge Description on Tuberculosis Clients}

\section{Muhammad Afif Hilmi Masyfahani 1, Tintin Sukartini2, Ririn Probowatis}

1. Mahasiswa Fakultas Keperawatan Universitas Airlangga

2. Fakultas Keperawatan Universitas Airlangga

3. STIKES Pemkab Jombang

\section{Riwayat artikel}

Diajukan: 3 Agustus 2019

Diterima: 28 Maret 2020

\section{Penulis Korespondensi:}

- Muhammad Afif Hilmi Masyfahani

- Fakultas Keperawatan, Universitas Airlangga masyfahani@gmail.com

\section{Kata Kunci:}

Self efficacy, Pengetahuan, Tuberkulosis

\section{Abstrak}

Pendahuluan: Tuberkulosis adalah salah satu penyakit menular yang tersebar di seluruh dunia dan menjadi masalah kesehatan masyarakat karena angka morbiditas dan mortalitas tinggi. Seiring dengan meningkatnya prevalensi kejadian Tuberkulosis. Tujuan : Mengetahui gambaran self efficacy dan pengetahuan klien Tuberkulosis di Rumah Sakit Umum Bangil. Metode : Penelitian deskriptif dengan pendekatan cross sectional. Sampel penelitian sebesar 70 responden dengan purposive sampling yang memenuhi kriteria inklusi dan eksklusi. Instrumen menggunakan kuesioner. Hasil : Hasil penelitian menunjukkan klien Tuberkulosis mempunyai self efficacy yang baik sebanyak 41 orang $(58,6 \%), \%)$, cukup sebanyak 20 orang $(28,6 \%)$ dan sisanya memiliki self efficacy kurang sebanyak 9 orang $(12,9 \%)$. dan memiliki pengetahuan yang baik sebanyak 36 orang $(51,4 \%)$. Klien Tuberkulosis juga memiliki pengetahuan yang baik sebanyak 36 orang $(51,4 \%)$, cukup sebanyak 24 orang $(34,3 \%)$ dan sisanya memiliki pengetahuan kurang sebanyak 10 orang $(14,3 \%)$. Kesimpulan : Keyakinan klien mengenai manajemen perawatan dirinya bisa meningkat dan mampu menghasilkan semangat untuk mencari pengetahuan, sikap positif dan keterampilan manajemen diri peningkatan dan perilaku kesehatan klien secara umum. Pengetahuan klien dengan memberikan informasi dan pemahaman melalui media modul pada klien Tuberkulosis mengenai penyakit Tuberkulosis sehingga dapat meningkatkan pengetahuan klien mengenai manajemen perawatan dirinya.

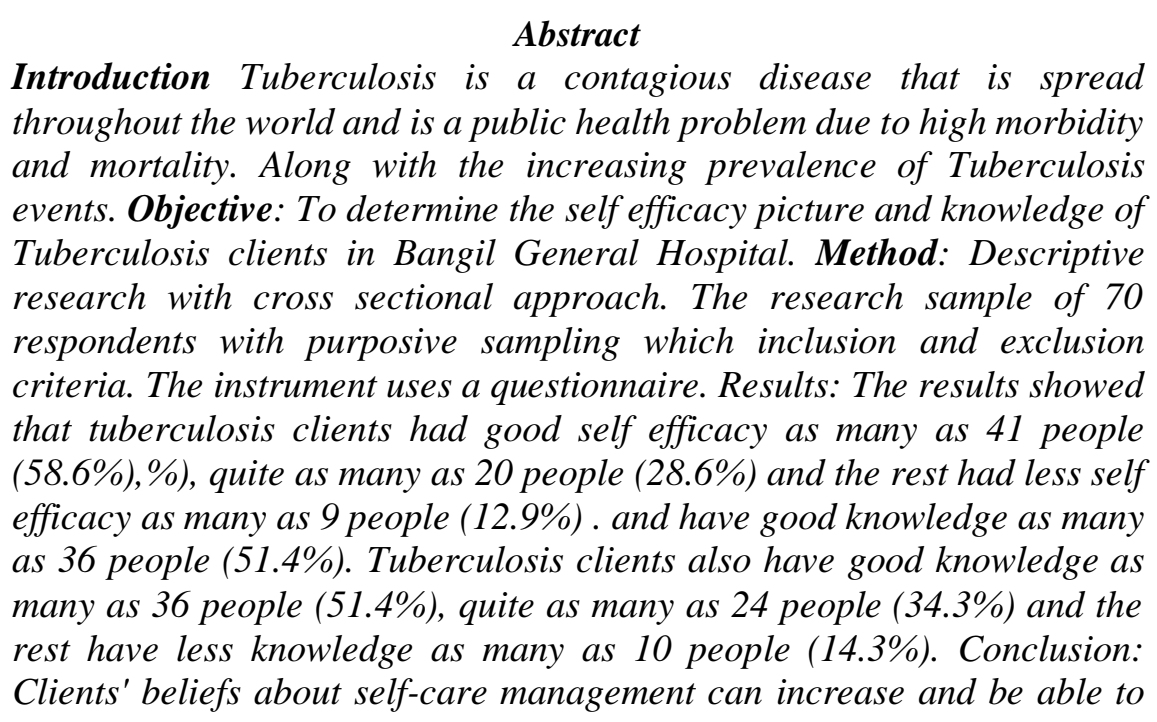

(Masyfahani, M.A.H, et al, 2020) 
generate enthusiasm to seek knowledge, positive attitudes and selfmanagement skills to improve and the client's health behavior in general. Client knowledge by providing information and understanding through a module media to the Tuberculosis client regarding Tuberculosis disease so as to increase the client's knowledge regarding management of her care.

\section{PENDAHULUAN}

Tuberkulosis merupakan salah satu penyakit menular yang tersebar di seluruh dunia dan menjadi masalah kesehatan masyarakat karena angka morbiditas dan mortalitas tinggi. Penyakit ini sulit untuk diatasi walaupun pengendalian dengan strategi Directly Observed Treatment, Shortcourse chemotherapy (DOTS) telah diterapkan sejak lama. Hal ini disebabkan pengobatannya lama dan diperlukan kepatuhan dari penderitanya. Dengan meningkatnya prevalensi kejadian Tuberkulosis tersebut, maka penanganan Klien Tuberkulosis selain pengobatan, kini berfokus pada pemberdayaan klien agar terlibat aktif dalam perawatan penyakitnya. Akan tetapi, pemberdayaan klien Tuberkulosis dalam mengelola penyakitnya sampai saat ini masih rendah. Semakin banyak kejadian multiple drug resistance (MDR) Tuberkulosis yang yang muncul sebagai akibat dari faktor putus obat Tuberkulosis. Hal ini menjadikan tingkat kompleksitas masalah Tuberkulosis menjadi semakin meningkat.

Profil Kesehatan Indonesia 2016 menempatkan penyakit Tuberkulosis sebagai yang pertama dalam prioritas pengendalian penyakit, dikarenakan penyakit Tuberkulosis mempunyai dampak yang luas terhadap kualitas hidup dan kasus kematian yang tinggi. Faktor yang berpengaruh dalam upaya menekan atau mengendalikan angka kejadian Tuberkulosis adalah keberhasilan pengobatan. Berdasarkan catatan Kemenkes RI 2016, angka keberhasilan pengobatan menurun drastis dari tahun - tahun sebelumnya. Sejak 7 tahun sebelumnya angka keberhasilan pengobatan berkisar pada 90,1\% sampai $92 \%$, kemudian menurun menjadi $85 \%$ (data per Juni 2016), angka tersebut masih di bawah target succes rate dari WHO yang menetapkan target > 85\% (Kementerian Kesehatan RI, 2016).

Jawa Timur merupakan salah satu provinsi di Indonesia yang angka kejadian Tuberkulosis parunya cukup tinggi.
Berdasarkan data yang diperoleh dari Riset Kesehatan Dasar (Riskesdas) pada tahun 2013, angka kejadian Tuberkulosis paru di Jawa Timur adalah 0,2 \%. Angka kejadian Tuberkulosis paru di Jawa Timur terus mengalami peningkatan setiap tahunnya yaitu pada tahun 2013 sebanyak 3660 kasus, tahun 2014 sebanyak 3896 kasus, tahun 2015 sebanyak 3914 kasus, dan pada tahun 2016 ditemukan sebanyak 3926 kasus yang tersebar dalam 19 kabupaten/ kota dalam Propinsi Jawa Timur termasuk Kabupaten Pasuruan.

Penelitian ini dilakukan untuk mengetahui gambaran self efficacy dan pengetahuan pada klien Tuberkulosis di Rumah Sakit Umum Bangil Pasuruan.

\section{METODE PENELITIAN}

Desain penelitian ini bersifat deskriptif secara cross sectional dengan mengumpulkan dan mengolah data untuk mengetahui gambaran self efficacy dan pengetahuan klien Tuberkulosis di RSUD Bangil Pasuruan. Sampel penelitian sebesar 70 responden dengan menggunakan tehnik purposive sampling. Kriteria inklusi pada penelitian ini adalah Klien Tuberkulosis Paru Primer yang telah memasuki fase pengobatan intensif (1-2 bulan pertama) yang tercatat di rekam medik, klien Tuberkulosis Paru berusia 26-45 tahun dan klien bisa membaca menulis. Kriteria eksklusi penelitian ini adalah klien dengan gangguan muskuloskeletal, pendengaran, kejiwaan, pendengaran dan penglihatan, klien Tuberkulosis dengan komplikasi dan yang hamil atau menyusui.

Alat dan bahan yang digunakan untuk memberikan intervensi self management education pada klien Tuberkulosis yaitu satuan acara kegiatan, modul, alat rekam, dan buku catatan untuk mencatat hal yang penting ketika pemberian intervensi self management education.

Instrumen penelitian menggunakan kuesioner untuk mengukur variabel self efficacy dan pengetahuan. Instrumen self efficacy menggunakan kuesioner yang 
berhubungan dengan self efficacy terkait kemampuan dalam menghadapi penyakit Tuberkulosis Paru yang terdiri dari 10 pertanyaan dengan menggunakan skala Guttman sebagai berikut ; $1=$ yakin dan $0=$ tidak yakin. Semuanya merupakan pertanyaan favourable. Nilai tertinggi adalah 10 dan terendah 0 . Semakin tinggi nilainya maka self efficacy semakin baik, demikian sebaliknya. Sedangkan Instrumen pengetahuan menggunakan kuesioner yang berhubungan dengan pengetahuan tentang Tuberkulosis Paru. Kuesioner pengetahuan yang digunakan dalam penelitian ini terdiri atas 10 pertanyaan yang terdiri dari 1 pertanyaan tentang pengertian Tuberkulosis Paru, 1 pertanyaan tentang tanda \& gejala Tuberkulosis Paru, 1 pertanyaan tentang pemeriksaan penyakit Tuberkulosis Paru, 1 pertanyaan tentang pengobatan Tuberkulosis Paru, 1 pertanyaan tentang efek samping pengobatan Tuberkulosis Paru, 2 pertanyaan tentang penunjang pengobatan Tuberkulosis, 2 pertanyaan tentang penularan Tuberkulosis Paru, 1 pertanyaan tentang pencegahan Tuberkulosis Paru. Semua pertanyaan merupakaan pertanyaan favourable. Kuesioner menggunakan pilihan ganda yang diberikan 3 pilihan jawaban. Jika jawaban responden benar, maka akan mendapatkan nilai 1 dan jika jawaban responden salah maka akan mendapatkan nilai 0 .

Lokasi untuk penelitian ini adalah Poli Paru RSUD Bangil Kabupaten Pasuruan. Waktu penelitian Maret-Agustus 2018. Teknik pengumpulan data adalah melakukan perijinan, setelah itu peneliti melakukan pengumpulan data dengan memberikan kuesioner kepada klien Tuberkulosis. Pengolahan data dalam penelitian ini melalui proses editing (memeriksa data, memeriksa jawaban, melakukan pengecekan terhadap data yang dikumpulkan dan memeriksa kelengkapan serta kesalahan), coding (memberi kode jawaban responden sesuai dengan indikator pada instrumen), transfering (memindahkan jawaban atau kode dalam media tertentu pada master tabel), tabulating (dari data mentah dilakukan penyesuaian data yang merupakan pengorganisasian data sedemikian rupa agar dengan mudah dapat di jumlah, disusun dan ditata untuk disajikan dan dianalisis).

\section{HASIL}

Pada data menginterpretasikan karakteristik umum responden yang meliputi usia, jenis kelamin, pendidikan terakhir, pekerjaan, status merokok, pernah mendapat pendidikan kesehatan.

Berdasarkan tabel 5.1 klien Tuberkulosis pada umumnya berjenis kelamin laki-laki dari pada perempuan sebanyak 46 orang $(65,7 \%)$. Usia penderita Tuberkulosis pada umumnya adalah usia dewasa awal sebesar 41 orang $(58,6 \%)$. Tingkat pendidikan pada klien Tuberkulosis sebagian besar berpendidikan SMP sebanyak 49 orang $(70 \%)$ yang merupakan sebagian besar mempunyai pekerjaan sebagai wiraswasta sebesar 40 orang $(57,1 \%)$. Sebesar $75,7 \%$ responden mengatakan merokok dan semuanya pernah mendapat pendidikan kesehatan (100\%).

Tabel tabel 5.2 menunjukkan bahwa sebagian besar klien Tuberkulosis memiliki self efficacy yang baik sebanyak 41 orang $(58,6 \%)$, cukup sebanyak 20 orang $(28,6 \%)$ dan sisanya memiliki self efficacy kurang sebanyak 9 orang $(12,9 \%)$.

Tabel tabel 5.3 menunjukkan bahwa sebagian besar klien Tuberkulosis memiliki pengetahuan yang baik sebanyak 36 orang $(51,4 \%)$, cukup sebanyak 24 orang $(34,3 \%)$ dan sisanya memiliki pengetahuan kurang sebanyak 10 orang $(14,3 \%)$.

\section{PEMBAHASAN}

Berdasakan hasil penelitian didapatkan hasil bahwa Sebanyak 70 klien Tuberkulosis pada umumnya berjenis kelamin laki-laki dari pada perempuan. Menurut WHO jumlah laki-laki yang meninggal akibat Tuberkulosis paru dalam satu tahun sedikitnya 1 juta orang, hal ini dapat terjadi karenakan laki-laki lebih mudah terpapar penyakit akibat penurunan sistem imun seperti Tuberkulosis paru akibat kebiasan laki-laki yang suka mengkonsumsi alkohol dan rokok. Hasil ini sejalan dengan penelitian yang dilakukan oleh Rini (2011) didapatkan hasil bahwa jenis kelamin yang paling banyak adalah laki-laki yaitu sebanyak 38 orang (56.8 \%). Rini menjelaskan 
penelitian di negara maju menunjukan bahwa laki-laki memiliki resiko tertular akibat kontak dan beraktifitas diluar lebih besar dari pada perempuan, sehingga lebih memudahkan penularan penyakit Tuberkulosis paru dari orang lain. 
Tabel 5.1 Distribusi Responden Berdasarkan jenis kelamin, usia, pendidikan terakhir, pekerjaan, status merokok, pernah mendapat pendidikan kesehatan

\begin{tabular}{lcc}
\hline Karakteristik & \multicolumn{2}{c}{ Jumlah } \\
\cline { 2 - 3 } Jenis Kelamin & $\mathrm{N}$ & $\%$ \\
\cline { 2 - 3 } Laki-laki & 46 & 65,7 \\
Perempuan & 24 & 34,3 \\
Usia & & \\
Dewasa Awal & 41 & 58.6 \\
Dewasa Akhir & 29 & 41.4 \\
Tingkat pendidikan & & \\
SMP & 49 & 70 \\
SMA & 21 & 30 \\
Pekerjaan & & \\
Pedagang & 23 & 32,9 \\
Wirasasta & 40 & 57,1 \\
Ibu rumah tangga & 7 & 10 \\
Status Merokok & & \\
Merokok & 53 & 75,7 \\
Tidak Merokok & 17 & 24,3 \\
Pernah PENKES & & \\
Ya & 70 & 100 \\
Tidak & 0 & 0 \\
\hline
\end{tabular}

Tabel 5.2 Distribusi frekuensi self efficacy klien Tuberkulosis

\begin{tabular}{lcc}
\hline \multirow{2}{*}{ Self efficacy } & \multicolumn{2}{c}{ Jumlah } \\
\cline { 2 - 3 } & $\mathrm{N}$ & $\%$ \\
\hline Baik & 41 & 58,6 \\
Cukup & 20 & 28,6 \\
Kurang & 9 & 12,9 \\
\hline Jumlah & 70 & 100 \\
\hline
\end{tabular}

Tabel 5.3 Distribusi frekuensi pengetahuan klien Tuberkulosis

\begin{tabular}{lcc}
\hline \multirow{2}{*}{ Pengetahuan } & \multicolumn{2}{c}{ Jumlah } \\
\cline { 2 - 3 } & $\mathrm{N}$ & $\%$ \\
\hline Baik & 36 & 51,4 \\
Cukup & 24 & 34,3 \\
Kurang & 10 & 14,3 \\
\hline Jumlah & 70 & 100 \\
\hline
\end{tabular}

Berdasarkan hasil penelitian yang telah dilakukan didapatkan bahwa usia penderita Tuberkulosis pada umumnya adalah usia dewasa awal sebanyak 41 orang $(58,6 \%)$. Menurut pendapat peneliti usia sangat berperan dalam angka kejadian penyakit Tuberkulosis. Hal ini sesuai dengan penelitian Umami (2016) yang menyatakan bahwa $75 \%$ karakteristik usia klien Tuberkulosis paru di Indonesia adalah kelompok dengan rentang antara usia 15-49 tahun yang merupakan kategori usia produktif. Hal ini menurut peneliti dikarenakan pada usia produktif terdapat kecenderungan untuk banyak melakukan interaksi dan memiliki mobilitas yang tinggi di luar rumah sehingga lebih rentan untuk tertular penyakit tuberkulosis. Hasil ini menunjukkan bahwa lebih dari separuh penderita terjadi pada kelompok usia produktif. Hal ini sesuai dengan laporan WHO (2017) sebelumnya dua per tiga kasus Tuberkulosis terjadi pada kelompok usia produktif secara ekonomi, yaitu 15 - 59 tahun.

Hasil penelitian menunjukan bahwa karakteristik tingkat pendidikan responden terbanyak adalah SMP sebanyak 49 orang (70\%). Tingkat pendidikan merupakan salah satu faktor pengendalian penularan penyakit Tuberkulosis paru. Pendidikan merupakan usaha dasar untuk mengembangkan kemampuan dan kepribadian yang berlangsung seumur hidup. Semakin tinggi pendidikan seseorang, semakin banyak pengetahuannya dan tinggi kesadarannya tentang hak yang dimilikinya untuk memperoleh informasi tentang upaya pengendalian penularan penyakit Tuberkulosis paru sehingga menuntut dirinya agar memperoleh keselamatan jiwanya. Rendahnya tingkat pendidikan akan berpengaruh pada pemahaman mengenai upaya pengendalian penularan penyakit Tuberkulosis paru. Sedangkan klien dengan tingkat pendidikan yang lebih tinggi akan mempengaruhi perilakunya dalam upaya pengendalian penularan penyakit Tuberkulosis paru.

Berdasarkan hasil penelitian menunjukan bahwa sebagian besar karakteristik pekerjaan responden adalah wiraswasta yang berjumlah 40 orang $(57,1 \%)$. Menurut peneliti hasil penelitian ini memiliki hubungan dengan tingkat aktivitas yang memungkinkan penularan kuman Tuberkulosis yang lebih mudah dari penderita Tuberkulosis paru. Pada dasarnya bekerja sebagai wiraswasta memiliki resiko lebih rentan tertular dengan penderita Tuberkulosis paru dikarenakan pekerja melakukan kontak dengan banyak orang.

\section{Self efficacy klien Tuberkulosis}

Hasil penelitian menunjukkan sebagian besar klien Tuberkulosis mempunyai self efficacy yang baik sebanyak 41 orang $(58,6 \%)$.

(Masyfahani, M.A.H, et al, 2020) 
Self efficacy dapat dicapai melalui pemberian motivasi dan meningkatkan keyakinan terhadap kemampuan diri dalam menghadapi penyakit Tuberkulosis. Klien mempunyai keyakinan yang kuat terhadap kemampuan yang dimiliki seperti keyakinan klien bahwa penyakitnya bisa disembuhkan dengan mengikuti pengobatan secara tuntas, klien juga termotivasi untuk tetap melanjutkan minum obat walau harus mengalami efek samping dari pengobatan, klien yakin bahwa banyak klien lain yang sembuh asal mau minum obat secara tepat dan tuntas, klien juga yakin terhadap diri sendiri bahwa dapat mengatasi segala rintangan yang dihadapi selama pengobatan dan dukungan keluarga selalu diberikan pada klien agar dapat menjalani aktivitas sehari-hari secara normal tanpa ada perasaan dihindari oleh orang lain.

Dalam sebuah penelitian yang dilakukan oleh Garrod (2008) self efficacy terbukti mempengaruhi keputusan individu untuk melakukan tindakan perawatan diri. Dikemukakan bahwa self efficacy bertindak sebagai mediator antara perubahan dalam kualitas hidup, gejala dan fungsi fisiologis pada kepatuhan berobat dan rehabilitasi paru. Pengukuran self efficacy dirancang untuk menguji keyakinan individu untuk melakukan kegiatan yang dipilih sebagai usaha yang diinginkan Garrod (2008). Self efficacy dapat memberikan prediksi terhadap kepatuhan seseorang dalam melakukan perawatan dirinya sendiri. Pada penderita Tuberkulosis paru selain faktor fisik, penting juga diperhatikan faktor psikologis antara lain pemahaman individu yang dapat mempengaruhi persepsi terhadap penyakit. Tuberkulosis paru merupakan contoh klasik penyakit yang tidak hanya menimbulkan dampak terhadap perubahan fisik, tetapi mental dan juga sosial. Bagi penderita Tuberkulosis paru dampak secara umum, batuk yang terus menerus, sesak nafas, nyeri dada, nafsu makan menurun, berat badan menurun, keringat pada malam hari dan kadang-kadang demam yang tinggi. Tidak sedikit klien yang ketika didiagnosis Tuberkulosis paru timbul ketakutan dalam dirinya, ketakutan itu dapat berupa ketakutan akan pengobatan, kematian, efek samping obat, menularkan penyakit ke orang lain, kehilangan pekerjaan, ditolak, dan didiskriminasikan (International Union AgaintsTuberculosis and Lung Disease, 2007). Ketidakpatuhan untuk berobat secara teratur bagi penderita Tuberkulosis paru tetap menjadi hambatan untuk mencapai angka kesembuhan yang tinggi. kebanyakan penderita tidak datang selama fase intensif karena tidak adekuatnya self efficacy pada dirinya yang mengakibatkan pengaruh motivasi terhadap kepatuhan berobat, besarnya angka ketidakpatuhan berobat akan mengakibatkan tingginya angka kegagalan pengobatan penderita Tuberkulosis paru dengan BTA yang resisten dengan pengobatan standar. Hal ini akan mempersulit pemberantasan penyakit Tuberkulosis paru di Indonesia.

Petugas kesehatan selalu memberikan motivasi untuk meningkatkan persepsi klien Tuberkulosis terkait manfaat perilaku pencegahan penularan penyakit Tuberkulosis, sehingga meningkatkan kesadaran dan motivasi untuk berlangsungnya perilaku sehat seperti menutup mulut saat batuk atau bersin, membuang dahak pada tempat khusus dan menggunakan masker. Petugas kesehatan juga membantu mengatasi hambatan yang dihadapi seperti kesulitan dalam pengobatan, kesulitan dalam memperoleh informasi terkait penyakit dan kebutuhan akan pengetahuan terkait penyakit. Hal ini memberikan dampak yang positif terhadap self efficacy yang berhubungan dengan pencegahan penularan dan melibatkan keluarga sebagai sumber utama interpersonal yang diharapkan dapat mendukung klien dalam perilaku pencegahan penularan Tuberkulosis dan dapat meningkatkan perilaku yang mempromosikan kesehatan dengan meningkatkan pemahaman klien terkait penyakit Tuberkulosis.

Bandura (1997) menyampaikan terdapat banyak bukti bahwa keberhasilan dan kesejahteraan manusia dapat dicapai dengan rasa optimis, ketika dalam realita sosial banyak sekali tantangan hidup seperti hambatan, kesengsaraan, kemunduran, frustasi dan ketidakadilan yang harus dihadapi. Seseorang harus mempunyai keyakinan keberhasilan yang kuat untuk dapat mempertahankan usahanya. Rasa self efficacy yang tinggi akan menimbulkan daya tahan terhadap hambatan dan kemunduran dari setiap kesulitan yang ada. Orang yang mengalami kecemasan akan mudah terserang depresi. Sedangkan orang yang mempunyai rasa self efficacy yang tinggi akan lebih mampu untuk melakukan berbagai usaha dan latihan serta mengotrol lingkungan sekitarnya.

\section{Pengetahuan klien Tuberkulosis}


Hasil penelitian menunjukkan sebagian besar klien Tuberkulosis memiliki pengetahuan yang baik sebanyak 36 orang $(51,4 \%)$. Pengetahuan secara keseluruhan dalam kategori baik karena klien dapat menjawab benar sebagian pertanyaan seperti penyakit Tuberkulosis dapat menular kepada orang lain melalui batuk/ bersin dan dahak, sinar matahari yang dapat membunuh kuman penyebab penyakit Tuberkulosis, mencegah penularan dengan minum obat anti Tuberkulosis (OAT) dengan teratur dan tuntas serta dengan pola makan yang sehat. Hal tersebut dapat dipengaruhi oleh informasi yang didapatkan klien sebelumnya dari petugas kesehatan di rumah sakit pada saat awal pengobatan Tuberkulosis atau dari sumber lain, namun klien menjawab salah untuk beberapa pertanyaan seperti klien Tuberkulosis harus tidur terpisah dengan anggota keluarga yang lain, dahak harus dibuang pada tempat khusus dan penyakit Tuberkulosis tidak dapat menular melalui keturunan. Hasil Penelitian ini menunjukkan bahwa pengetahuan klien yang berfokus pada tentang manfaat dari perilaku pencegahan penularan Tuberkulosis tergolong baik, petugas kesehatan membantu mengatasi hambatan yang dialami klien dalam mendapatkan informasi tentang pencegahan penularan Tuberkulosis dengan memberikan penjelasan konsep penyakit Tuberkulosis dan melibatkan dukungan dari keluarga yang terbukti meningkatkan pengetahuan klien terkait pencegahan penularan Tuberkulosis.

Selain penyuluhan yang diberikan petugas kesehatan, klien juga memperoleh pengetahuan dari sumber-sumber informasi lain yang dapat diperoleh seperti : koran, TV, Majalah, Radio dan pengalaman tetangga. Jika keluarga jarang terpapar dengan sumber informasi tersebut maka, keluarga hanya memperoleh sedikit informasi tentang kesehatan penderita. Penerimaan atau penangkapan informasi yang diterima keluarga juga dapat dipengaruhi oleh tingkat pendidikan keluarga yang mayoritas berpendidikan SMP, yang tergolong dalam kategori pendidikan rendah sehingga mempengaruhi keluarga dalam penyerapan informasi.

Meningkatnya pengetahuan klien adalah salah satu tercapainya tujuan edukasi. Dengan demikian meningkat juga kesadaran diri dari segi kesehatan, merubah gaya hidup ke arah yang sehat, patuh terhadap terapi dan berkualitas. Pengetahuan yang baik sangat diharapkan dalam mencegah dan menanggulangi penyakit Tuberkulosis. Tingkat pengetahuan yang rendah dalam upaya mencegah dan menanggulangi penyakit Tuberkulosis dapat menjadi faktor resiko terjadinya penularan Tuberkulosis. Pengetahuan yang kurang dapat terjadi karena minimnya informasi serta tidak adekuatnya informasi yang didapatkan dan diterima oleh responden.

Hasil ini sesuai dengan penelitian oleh El Hameed (2014) tentang program perawatan diri pada klien Tuberkulosis hasilnya adalah peningkatan yang signifikan pada pengetahuan dan kemampuan mengelola fisik dan berdampak pada kondisi fisik, mental dan sosial klien Tuberkulosis pada orang dewasa. Artinya program yang berkaitan hasil dan tujuan yang jelas akan membuat klien mampu meningkatkan pengetahuan dan mencapai tujuan yang di tetapkan. Klien yang ingin cepat sembuh, mampu melakukan keperawatan sendiri untuk mempercepat proses penyembuhan. Hal ini juga di dukung oleh penelitian program suportif edukasi pada klien Tuberkulosis di masyarakat juga di lakukan Umami (2016) dengan hasil penelitian bahwa pendidikan kesehatan mampu meningkatkan Pengetahuan dan Sikap Penderita dalam Pencegahan Penularan Tuberkulosis klien Tuberkulosis di rumah.

Penelitian yang lain dilakukan oleh Ridlwan (2018) mengemukakan bahwa pengetahuan klien tentang diet DM tipe 2 merupakan hal yang penting guna mencapai kepatuhan menjalani diet sehingga terbentuk perilaku kepatuhan. Peningkatan pengetahuan menjalani diet pada DM tipe 2 memerlukan peran serta tenaga kesehatan untuk memberikan informasi yang tepat untuk mengontrol pola makan pada penderita DM tipe 2. Pengetahuan klien yang baik adalah salah satu faktor yang juga meningkatkan kesadaran diri klien dari segi kesehatan, merubah gaya hidup kearah yang sehat, patuh terhadap terapi dan berkualitas.

\section{KESIMPULAN}

Berdasarkan hasil penelitian dan pembahasan yang telah dilakukan dapat disimpulkan bahwa:

1. Sebagian besar klien Tuberkulosis mempunyai self efficacy yang baik sebanyak 41 orang $(58,6 \%)$. Keyakinan 
klien mengenai manajemen perawatan dirinya bisa meningkat dan mampu menghasilkan semangat untuk mencari pengetahuan, sikap positif dan keterampilan manajemen diri peningkatan dan perilaku kesehatan klien secara umum.

2. Sebagian besar klien Tuberkulosis memiliki pengetahuan yang baik sebanyak 36 orang $(51,4 \%)$. Pengetahuan klien dengan memberikan informasi dan pemahaman melalui media modul pada klien Tuberkulosis mengenai penyakit Tuberkulosis sehingga dapat meningkatkan pengetahuan klien mengenai manajemen perawatan dirinya.

\section{SARAN}

Diharapkan bagi klien Tuberkulosis selalu meningkatkan kesadaran untuk mencari informasi mengenai penyakit Tuberkulosis dalam upaya meningkatkan pemberdayaannya serta mempraktikan edukasi yang diberikan dalam kehidupan sehari-hari.

\section{DAFTAR PUSTAKA}

Addisu, Y., Birhanu, Z., Tilahun, D., \& Assefa, T., 2014 'Predictor Of Treatment Seeking Intention Among People With Cough In East Wollega, Ethiopia Based On The Theory Of Planned Behavior: A Community Based Cross-Sectional Study', Ethiop J Health Sci, 24(2). doi: http://dx.doi.org/10.4314/ejhs.v24i2.5.

Adiatama, Tjandra Y., 2000. Tuberkulosis: Diagnosis, Terapi dan Masalahnya. Jakarta : Laboratorium Mikobakteriologi RSUP Persahabatan / WHO Collaborating Center for Tuberculosis

Alligood,M.R.\&Tomey,A.M., 2006. Nursing Theorists and Their Work, 6th. ed, Mosby Missouri.

Alligood,M.R.\&Tomey,A.M., 2017. Pakar Teori Keperawatan dan Karya Mereka, Edisi Indonesia ke-8 Volume 2, Elsevier, Singapura.

Almatser, S., 2004. Penuntun Diit. PT. Gramedia Pustaka Utara. Jakarta

Alsagaff, H. and Mukty, A., 2005. Dasar-dasar ilmu penyakit paru. Surabaya: Airlangga University Press.

Amin, Z. and Bahar, A., 2009. Ilmu Penyakit Dalam Jilid III. V. Jakarta: Balai Penerbit FK UI.

Bandura, A. (1997). Self efficacy In V. S.
Ramachaudran (Ed.), Encyclopedia of human behavior (Vol. 4, pp. 71-81). New York: Academic Press. (Reprinted in H. Friedman [Ed.], Encyclopedia of mental health. San Diego: Academic Press, 1998).

Bravo, P., Edwards, A., Barr, P. J., Scholl, I., Elwyn, G., \& McAllister, M. 2015. Conceptualising patient empowerment: a mixed methods study. BMC Health Services Research, 15(1), 252

Bourbeau, Cosgrove, D., Macmahon, J., , J., Bradley, J. M., \& O’Neill, B., 2013. Facilitating education in pulmonary rehabilitation using the living well with COPD programme for pulmonary rehabilitation: a process evaluation. $B M C$ Pulmonary Medicine, 13(1), 50.

Costa, A., Emmanuel, P., Ingebourg, G., Paiva, E., Cavalcanti, V., 2017 'Clinical Nutrition ESPEN Dietary counseling adherence during tuberculosis treatment: A longitudinal study', Clinical Nutrition ESPEN, 17, pp. 44-53. doi: 10.1016/j.clnesp.2016.11.001.

Depkes, RI \& WHO., 2002. 'Lembar Fakta Tuberkulosis'. Hari Tuberkulosis Sedunia 24 Maret 2002.

Depkes RI., (2002). Pedoman Nasional Penanggulangan Tuberkulosis. Jakarta : Depkes RI hal. 8: 3- 47

Dharma, K., 2011. Metodologi Penelitian Keperawatan: Panduan Melaksanakan dan Menerapkan Hasil Penelitian. Jakarta: Trans Info Media.

Dotulong, J. F. J., Sapulete, M. R. and Kandou, G. D., 2015 'Hubungan Faktor Risiko Umur, Jenis Kelamin dan Kepadatan Hunian dengan Kejadian Penyakit TUBERKULOSIS Paru di Desa Wori Kecamatan Wori', Jurnal Kedokteran Komunitas dan Tropik, III, pp. 57-65.

Efraimsson, E. Ö., Hillervik, C., \& Ehrenberg, A., 2008. Effects of COPD self-care management education at a nurse-led primary health care clinic. Scandinavian Journal of Caring Sciences, 22(5), 178185.

El Hameed, B., 2014. Pengaruh program Self care terhadap pemberdayaan pasien Tuberkulosis di Puskesmas Kabupaten Maluku Tenggara. Tesis. Yogyakarta : Universitas Gajah Mada

Garrod, R, Marshall, J, Jones, F., 2008. Self efficacy measurement and goal 
attainment after pulmonary rehabilitation. Int $J$ Chron Obstruct Pulmon Dis. ;3:791-796

Green, 2005. Health Education Planing a Diagnostic Approach. Johns Hapkins University: Mayfield Pub Co.

Harpita, P. and Padmawati, R., 2017 'Efektifitas Pendidikan Kesehatan Melalui Multimedia dan Tatap Muka terhadap Pengetahuan dan Sikap Ibu Hamil tentang ASI dan Menyusui', Jurnal Care, 5, pp. 156-167.

Ho, C. and Lee, T.,2014. 'An Evaluation Of Medication Adherence In Hypertensive Patients Using The Theory Of Planned Behavior', value In Health, 7(PCV45), p. A763. doi: 10.1016/j.jval.2014.08.270.

Indrawati, L., 2012. 'Upaya Meningkatkan Perilaku Preventif Remaja Melalui Pendidikan Kesehatan dengan Pendekatan HPM (HPM) Infeksi Menular Seksual (IMS)', Tesis, Universitas Airlangga Surabaya.

IUATLD.,2008. Nutrition and Tuberculosis. A Review of the Literature and Considerations for Tuberkulosis Control Program.

Kemenkes.,2014. Pedoman Nasional Pengendalian Tuberkulosis. Edited by T. Dini hari. Jakarta: Kementrian Kesehatan RI.

Kementerian Kesehatan RI., 2016. Profil Kesehatan Indonesia 2015. Edited by D. Budijanto. Kementrian Kesehatan RI. doi: 351.077 Ind.

Lin, C., Updegraff, J. A. and Pakpour, A. H., 2016. 'Epilepsy \& Behavior The relationship between the theory of planned behavior and medication adherence in patients with epilepsy', Epilepsy \& Behavior. Elsevier Inc., 61, pp. 231-236. doi: 10.1016/j.yebeh.2016.05.030.

Machfudli, 2016. 'Pengaruh modifikasi model asuhan keperawatan adaptasi Roy terhadap self efficacy, respon penerimaan dan respon biologis pada pasien tuberkulosisi paru', Disertasi, Universitas Airlangga, Surabaya

Marcinkho, S., 2008. The wellness planner: Testing an intervention designed to increase empowerment and improve quality of life in individuals with mental illness. University of Manitoba
(Canada)). ProQuest Dissertations and Theses, , n/a. Retrieved from http://search.proquest.com/docview/304 402398? accountid $=17242$

Ministry of Health., 2014. Self-management Support for people with long-term conditions, (November), 1-7.

Monteagudo, M., 2013. Factors associated with changes in quality of life of COPD patients: a prospective study in primary care. Respiratory Medicine, 107(10), 1589-97.

Monteagudo M, Rodriguez-Blanco $\mathrm{T}$, Llagostera M.,2013. Effect of health professional education on outcomes of chronic obstructive pulmonary disease in primary care: a non-randomized clinical trial. Respirology., 18, 718-727.

Notoatmodjo, S., 2012. Promosi Kesehatan dan Perilaku Kesehatan. Revisi, 20. Jakarta: Rineka Cipta.

Nugroho, S. A., 2016. 'Hubungan Antara Pengetahuan Penderita Tuberculosis Dan Dukungan Keluarga Dengan Kepatuhan Menelan obat Di Wilayah Kerja Puskesmas Jekulo Kabupaten Kudus'.

Nursalam. 2016. Metodologi Penelitian Ilmu Keperawatan Pendekatan Praktis. 4th edn. Edited by P. Lestari. Jakarta Selatan: Salemba Medika.

Nursalam. (2014). Manajemen Keperawatan.edisi 3. Jakarta : Salemba Medika

Pameswari, P., Halim, A. and Yustika, L. (2016) 'Tingkat Kepatuhan Penggunaan Obat pada Klien Tuberkulosis di Rumah Sakit Mayjen H . A . Thalib Kabupaten Price (2006) Patofisiologi Vol 2: Konsep Kllinis Proses-proses Penyakit. Jakarta: EGC.

Potter \& Perry., 2005. Buku Ajar Fundamental Keperawatan Konsep, Proses, dan Praktik. Edisi 4 volume 1.EGC. Jakarta

Pender, N.J., Murdaugh, C. and Parsons, M.A. (2002). Health Promotion in Nursing Practice. 4th Edition, Prentice-Hall Health, Inc., USA, 140-145

Rosyida, L., 2015. 'Kepatuhan Klien Pada Penggunaan Obat Antidiabetes Dengan Metode Pill-Count Dan MMAS-8 Di Puskesmas Kedurus Surabaya', Jurbak Farmasu Komunitas, 2(2), pp. 36-41.

Ridwan,A., 2018. Efektivitas Diabetes Self Management Education melalui SMS terhadap pengetahuan Penderita Diabetes 
Mellitus. Idea Nursing Journal.Vol IX. No. I 2018

Rini, Ika S., 2011. Hubungan antara efikasi diri dengan kualitas hidup klien penyakit paru obstruksi kronik dalam konteks asuhan keperawatan di RS Paru Batu dan RSU Dr Saiful Anwar Malang Jawa Timur. Tesis. universitas Indonesia. Tidak dipublikasikan

Sarwono, S. W., 2012. Psikologi Remaja. Jakarta: PT. Raja Garlindo Persada.

Sastroasmoro dan Ismail., 2011, Dasar-dasar metodologi penelitian klinis, Sagung Seto, Jakarta.

Smeltzer, S. and Bare, B., 2009. Buku Ajar Keperawatan Medikal Bedah Brunner \& Suddarth. (Edisi 8 V. Jakarta: EGC.

Stark, E. and John., 2002. Manual Ilmu Penyakit Paru. Jakarta: Binarupa Aksara.

Stellefson, M., Tennant, B., Don, J., 2012. A critical review of effects of COP Self Management Education on Self efficacy. Journal Public Health, Vol.1, no.2012, hal 1-10.

Sukartini, Tintin, 2015. Pengembangan model peningkatan kepatuhan berbasis teori sistem interaksi King dan pengaruhnya terhadap kepatuhan pasien tuberkulosis paru', Disertasi, Universitas Indonesia, Depok

Sunaryo, 2004. Psikologi untuk Keperawatan. Jakarta: EGC.

Spalding., 2004. Preoperative education ; empowering patients with confidence. International Journal Rehabilitation. $\mathrm{N}(4) ; 147-153$

Tobing, T, L.,2009. 'Pengaruh perilaku klien Tuberkulosis paru dan kondisi rumah terhadap pencegahan potensi penularan Tuberkulosis paru pada keluarga di kabupaten Tapanuli utara tahun 2008.', Tesis http: repository.usu.ac.id diunduh 24 September 2017.

Turner, A., Anderson, J., Wallace, L., \& Kennedy-Williams, P., 2014. Evaluation of a self-management programme for patients with chronic obstructive pulmonary disease. Chronic Respiratory Disease, 11(3), 163-172.

Umami, Y.H., 2016. Pengaruh Pendidikan Kesehatan tentang Tuberkulosis Terhadap Peningkatan Pengetahuan dan Sikap Penderita dalam Pencegahan Penularan Tuberkulosis di Puskesmas
Simo', p.1-15

Valero $C$, Monteagudo $\mathrm{M}$, Llagostera $\mathrm{M}$, Bayona X, Granollers S, Acedo M., 2009. Evaluation of a combined strategy directed towards health-care professionals and patients with chronic obstructive pulmonary disease (COPD): Information and health education feedback for improving clinical monitoring and quality-of-life. $B M C$ Public Health, 9(1), 442.

WHO, 2017. Global Tuberculosis Report. 20th edn. France: WHO Library Cataloguingin-Publication Data.

Widoyono, 2011. Penyakit Tropis Epidemiologi,Penularan,Pencegahan Dan Pemberantasannya. Jakarta: Erlangga. 